\title{
Lightning Protection Design for 10kV Composite Distribution Tower
}

\author{
Jin-Tang $\mathrm{HAO}^{1, \mathrm{a}}$, Xi LIU ${ }^{2}$, Xia XU², Gang LIU ${ }^{2}$, Tian-Zheng WANG ${ }^{1}$, \\ Jian-Ping $\mathrm{HUANG}^{3, \mathrm{~b},{ }^{*}}$ \\ ${ }^{1}$ State Grid Shanxi Electric Power Research Institute, Taiyuan 030001, China \\ ${ }^{2}$ Wuhan NARI Limited Company Of State Grid Electric Power Research Institute, Wuhan 430074, \\ China \\ ${ }^{3}$ Wuhan Hongmen Electrical Company, Wuhan 430074, China \\ alucky94515@163.com, b46980712@qq.com \\ ${ }^{*}$ Corresponding author
}

Keywords: 10kV Composite Distribution Tower, Lightning Protection Design, Grounding Mode, Parameter Optimization.

\begin{abstract}
Lightning protection design for $10 \mathrm{kV}$ composite distribution tower differs from transmission towers and the traditional iron tower due to the insulation of composite material and complexity of lightning protection design for $10 \mathrm{kV}$ distribution lines. Related research is still in blank. Key points of lightning protection design are discussed based on the simulation study on the overvoltage characteristic of direct lightning and induction lightning of $10 \mathrm{kV}$ composite distribution tower with or without the grounding wire. The result shows that composite tower without grounding wire is suitable for regions where induction lightning is the main risk and the key point is to transfer the flashover path in order to avoid the arc burning the composite tower; Composite tower with grounding wire is suitable for regions where direct lightning is the main risk and the key points are to improve the insulation strength between phase and the ground in order to enhance the induction lightning withstanding level and to improve the insulation strength between phases to avoid double phase flashover before the release of the lightning current. According to the key points, structural parameter optimization is carried out.
\end{abstract}

\section{Introduction}

With the development of composite material preparation technology recently, the composite is widely applied in power transmission and distribution system as structural material ${ }^{[1]}$. Make rational use of the excellent insulation of composite distribution tower can improve lightning withstand level. Domestic and foreign scholars carried out many related researches and practice for a long time. A Canadian company called RS and an American company named Ebert mastered the mature technology of composite preparation in the mid-1990s. The composite appeared in China later than in Europe $^{[2,3]}$, China did not began to research until the year of 2009. Demonstration projects built in several places, such as a $220 \mathrm{kV}$ project in Lianyungang, a $110 \mathrm{kV}$ project in Yanqing County of Beijing and a $10 \mathrm{kV}$ in Fangshan County of Beijing ${ }^{[4,5]}$. But so far the technical standard and criterion of composite's application in power transmission has not yet enacted ${ }^{[6]}$. Under the conditions of small distance between $10 \mathrm{kV}$ distribution lines tower, direct lightning and inductive lightning strikes would be the main reason to cause trip. Lightning protection design for $10 \mathrm{kV}$ composite distribution tower differs from transmission towers ${ }^{[7,8]}$. So we need to do further research in structural parameter optimization of lightning protection design for $10 \mathrm{kV}$ composite distribution tower.

According to its design features, main technical measures of the $10 \mathrm{kV}$ composite distribution tower' are concluded in this paper. Study on the overvoltage characteristic of direct lightning and induction lightning of $10 \mathrm{kV}$ composite distribution tower. Structural parameter optimization and improvement suggestions are also put forward. 


\section{Design for 10kV Composite Distribution Tower}

\section{Criteria of Lightning Trip}

Unlike neutral directly grounding used in $110 \mathrm{kV}$ or higher voltage grounded system, neutral of $10 \mathrm{kV}$ transmission line usually use low resistance connecting with grounding, as well as arc-suppression coil ground. Power frequency current in neutral indirect grounded system is smaller than in neutral directly grounding. So tower of $10 \mathrm{kV}$ transmission line can't lightning trip or break line without enough energy from current. The main reason for the trip is two-phase flashover. According to the basic structure of $10 \mathrm{kV}$ composite distribution tower, the form of two-phase flashover including two-phase flashover occurs directly and earth connecting cable indirectly leads to two-phase flashover.

In the design of lightning protection $10 \mathrm{kV}$ composite distributions tower involving six gaps. We can see it from figure $1 . L_{1}$ is air gap that phase to the top line $\mathrm{L}_{2}$ is air gap that two sides phase along the surface of composite tower; $\mathrm{L}_{3}$ is top phase to cross arm along the compound tower air gap; $\mathrm{L}_{4}$ $\left(\mathrm{L}_{40}\right)$ is air gap between earth connecting cable and adjacency phase and $\mathrm{L}_{5}$ is air gap between earth connecting cable and top phase; $\mathrm{L}_{6}$ is the air gap between cross arm and adjacency phase along the surface of composite tower. When the composite tower erected insulator, there should be air gap on the surface of the insulator. Thus, the paths of two-phase flashover directly are including $\mathrm{L}_{1}$ and $\mathrm{L}_{2}$. Paths of two-phase flashover indirectly are including $\mathrm{L}_{40}, \mathrm{~L}_{4}$ and $\mathrm{L}_{5}$.

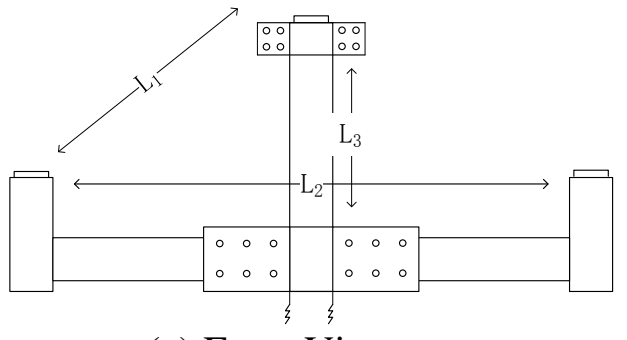

(a) Front View

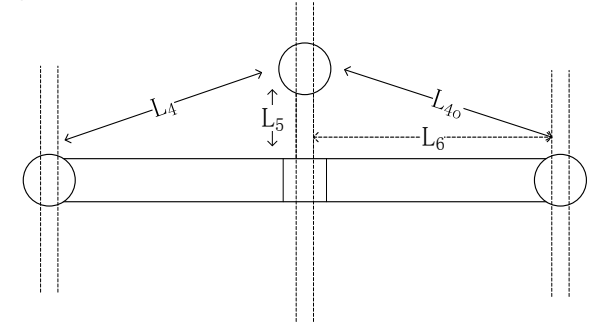

(b) Top View

Fig.1 Air Gaps in 10kV Composite Distribution Tower

\section{Type of Overvoltage}

Induction lightning is main concerns for traditional distribution line lightning protection method. The impact of direct lightning on calculation results of lighting withstand level totally be neglected. This method is applicable in the place with high barrier such as downtown and the town area with tall buildings, towers, triggering lightning tower. But for shield less regions, such as grassland, farmland, mountains, the impact of direct lightning can't be ignored. It is an important factor in lightning protection design. The modes of grounding wires and parameters of towers often differ from others. There are different features of overvoltage in direct lightning and induction lightning. So it is necessary to consider direct lightning overvoltage and induction lightning overvoltage for lightning protection design.

\section{Mode of Grounding Wire}

There are many divergences under the mode of grounding wire. Canada suggests composite tower shouldn't set up lightning protection conductor. The reason is composite tower have good insulation and low arcing rate. So without lightning protection conductor wire, the lightning-proof of composite tower is better than power line tower in same voltage level. Another point suggests that the composite material tower's lightning protection conductor can release lightning overvoltage. Grounding wire mode for $10 \mathrm{kV}$ power distribution tower need demonstration, in order to satisfy the requirement of the lightning strike and induction thunder lightning protection. There are three ways of common models: directly grounding method in every tower, directly grounding method interval in tower and grounding through grounding wire in gap ${ }^{[3]}$.

According to the problems expatiated in the paper, structural parameter optimization for composite 
material tower of $10 \mathrm{kV}$ is carried out.

\section{Characteristic of Overvoltage in Composite Distribution Tower}

\section{Simulation Model}

In this paper, we use JMarti transmission line model [9] to calculate the overvoltage of directly lightning. In 13th reference, Bergeron model that derived from TL model used to calculate the overvoltage of induction lightning. Two method of calculation will realize in ATPdraw platform.

\section{Overvoltage and Flashover Performance}

We assume that the distance between the tower and the grounding wire is 0.5 kilometer.

According 14th reference, discharge voltage gradient of 50\% lightning stroke in composite tower is $407 \mathrm{kV} / \mathrm{m}$; discharge voltage gradient of $50 \%$ lightning stroke in air gap is $750 \mathrm{kV} / \mathrm{m}$.

Characteristics of Overvoltage without Grounding Wire. The flashover paths are $\mathrm{L}_{1}, \mathrm{~L}_{2}$ and $\mathrm{L}_{3}$ air gaps in figure 1. And this creates three two-phase flashover paths $\mathrm{W}_{1}, \mathrm{~W}_{2}$ and $\mathrm{W}_{3}$ in the figure 2 . By using 50\% lightning stroke voltage of each path, we calculated lightning impulse withstand level. When lightning edge phase and lightning top phase, the lightning impulse withstand level of direct lightning average $3 \mathrm{kA}$. Although amplitude of lightning current is $1.3 \mathrm{high}$ compare with iron tower. According to the formula that amplitude of lightning current, chances of amplitude higher than 3kA is $92.45 \%$. So the direct lightning strike tripping is still exists in composite tower of $10 \mathrm{kV}$. Considering some composite tower don't have insulator, flashover path would change into W2 or W3. The burning arc may burn composite tower.

When lighting forming and changing, it can regard as a quasi-static equilibrium. Relaxation time constant is about $3 \mu \mathrm{s}$ [10]. Distance between composite towers of $10 \mathrm{kV}$ usually is small. When induction lightning occurs, charge accumulation process usually same. It causes the phase-phase induction lightning overvoltage is small. Different from the iron tower is isolating potential between conductor and ground. Composite tower distance between phase and ground increased greatly because the isolation. Whether the phase-ground voltage or induction lightning voltage, they won't cause phase-phase flashover. We can make a conclusion that there is no risk of tripping to the composite tower of $10 \mathrm{kV}$ without grounding wire.

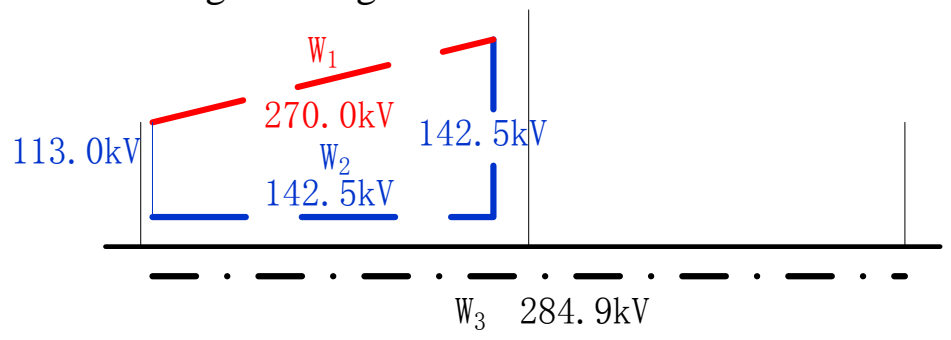

Fig. $2 \mathrm{U}_{50 \%}$ of Different Flashover Path

Characteristic of Overvoltage with Grounding Wire. When composite tower with a grounding wire, it equivalent composite tower was short circuit. The characteristics of flashover in direct lightning and induction lightning is different.

The simulation results reflect that when lightning flashover phase to ground happened first, overvoltage of induction lightning decreases. In fact, lightning phase provides lightning flashover channel first. At the same time, the discharge of the lightning current reduces the lightning induced voltage and coupling voltage. So, the grounding wire is useful in raise the lightning impulse withstand level of composite tower. Make sure two-phase flashover won't happen before phase-ground flashover, can improve the lightning impulse withstand level effectively. Differ from direct lightning, the flashover between induction lightning overvoltage and phase to grounding wire is usually happen in many phases. So, when design mine-protected after mounted grounding wire, we must ensure phase dielectric strength between the ground lead to tolerate higher amplitude phase 
between the inductions lightning.

Characteristic of Overvoltage when Interval Grounding Tower. Different from grounding in every tower, interval grounding means grounding every other tower. Simulation results in firgure 3 shows, when lightning strikes top phase and edge phase, phase-phase flashover happen in the tower which strike by direct lightning. Then the front tower stroked phase will flashover to the grounding wire. It means the phase-ground flashover happened in tower can't protect tower next it which without grounding wire, grounding in every tower is better than interval grounding.

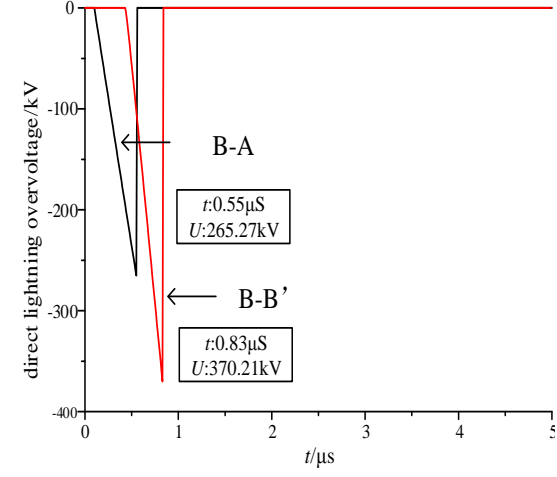

(a) Lightning Edge Phase, 10kA

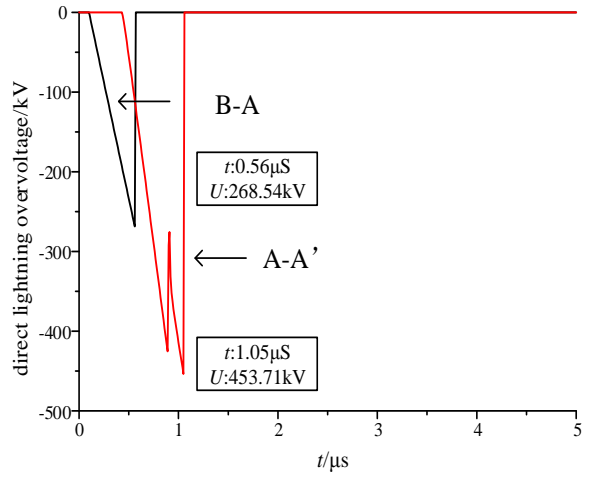

(b) Lightning Edge Phase, 50kA

Fig.3 Overvoltage Characteristic of Direct Lightning (Interval Grounding)

\section{Optimization Design of Composite Distribution Tower}

Structural parameter optimization to composite tower of $10 \mathrm{kV}$ was based on characteristics of flashover and overvoltage.

\section{Structural Parameter Optimization}

There is no risk of induction lightning flashover to composite tower of $10 \mathrm{kV}$ without grounding wire. So, this kind of way to erect grounding wire is suitable in urban city where the shield is large. Induction lightning also exists in these areas. So, on the Structural Parameter design, we can reduce the size of tower under premise condition of windage yaw, withstand pollution and wet withstand voltage.

When take induction lightning into consideration, the lightning withstand level of direct lightning is low, so the structural parameter optimization to improve lightning withstand level is not obvious. The important part of structural parameter optimization should be focus on make phase to phase flashover happen in the air gap $\mathrm{L}_{1}$. It can protect composite tower from arc ignition.

Grounding composite tower can inhibit lightning overvoltage. When it land in empty suburb or farmland where the shield is less. The composite tower of $10 \mathrm{kV}$ can grounding in every tower. When structural parameter optimization, direct lightning overvoltage and induction lightning overvoltage are influenced it simultaneously. So the structural parameter optimization should satisfy the two kinds of overvoltage requirements.

Optimization According to the Requirements of Induction Lightning. According to induction lightning overvoltage characteristics after it erect grounding wire, improve the induction lightning withstand level should improve the dielectric strength of every phase and grounding wire. So, dielectric strength of gap $\mathrm{L}_{4}$ and $\mathrm{L}_{5}+\mathrm{L}_{6}$ should strong than induction lightning overvoltage. Calculating the different lightning location, distance $d_{i}$ and lightning current amplitude $I_{\max }$ with the lightning overvoltage could preliminary estimate the discloser for lightning protection design. The probability of lightning current amplitude over $100 \mathrm{kA}$ is only $7 \%$. The probability of lightning 
current amplitude over $150 \mathrm{kA}$ is only $2 \%$. So, we can use lightning current amplitude 100kA corresponding induction lightning overvoltage $279 \mathrm{kV}$ or $150 \mathrm{kA}$ corresponding $420 \mathrm{kV}$.

Optimization According to the Requirements of Direct Lightning. On the basis of direct lightning overvoltage characteristics with grounding wire, using grounding wire to discharge lightning current can raise the level of direct lightning withstand level. And it must meet the following requirements: 1) Two phase directly flashover can't happen before single-phase flashover occurred to the lightning strike phase; 2)Flashover path of phase to grounding wire was in line air gap; We can know from the results in figure 6, phase-phase overvoltage happened before phase-ground direct lightning was no more than $250 \mathrm{kV}$. Consider a certain margin, we choose $300 \mathrm{kV}$ as design standard. According to the conditions, the shortest cross arm length is $0.74 \mathrm{~m}$. Combine with the induction lightning overvoltage requirements, final optimization solution list in table 1.

Tab.1 Optimal Structure Parameter

\begin{tabular}{ccc}
\hline $\begin{array}{c}\text { Distance between tower and } \\
\text { grounding wire L[m] }\end{array}$ & $\begin{array}{c}\text { Length of cross arm } \\
\mathrm{d}[\mathrm{m}]\end{array}$ & $\begin{array}{c}\text { Distance between tower and } \\
\text { grounding wire } \mathrm{h}[\mathrm{m}]\end{array}$ \\
\hline 0.3 & $>0.96$ & - \\
0.4 & $>0.79$ & $>0.10$ \\
0.5 & $>0.74$ & $>0.15$ \\
\hline
\end{tabular}

\section{Conclusions}

1) Lightning protection design for $10 \mathrm{kV}$ composite distribution tower differs from transmission towers and the traditional iron tower. Two phase flashover is needed to be the basic criterion of flashover and main lightning trip. At the same time, for the requirement of induction lightning over-voltage and lightning overvoltage grounding lead the way, the composite tower should be avoided burning by arc.

2) The $10 \mathrm{kV}$ composite distribution tower without the grounding wire is suitable for areas where direct lightning is regarded as the main risk. The focus is to transfer in optimizing the structure of the flashover path and avoid the little direct lightning arc burning composite tower.

3) For the $10 \mathrm{kV}$ composite distribution tower with the grounding wire, it is suitable for areas where direct lightning overvoltage may happen frequently. The key points are to improve the insulation strength between phase and the ground.

4) Structural parameter optimization is carried out according to the two styles of grounding wire. Optimal structure parameters and the corresponding configuration mode are showed respectively in detail.

\section{Acknowledgement}

This research was financially supported by the technology project of State Grid Corporation of China, research of improving the technology on AC/DC overhead transmission line lightning flashover restrictions.

\section{References}

[1] Zhang Xiongjun. Application andprospect of composite tower [J]. Fiber Reinforced Plastics/Composites, 2012(S1): 301-306.

[2] Liu Hanli. Research and application of composite transmission poles and towers [J]. Fiber Composites, 2011(3): 38-40. 
[3] Yang Minxiang, Chen Yuan, Li Weiguo, et al. Research progress on composite tower and pole and its key technical problems [J]. North China Electric Power, 2010(10): 48-50.

[4] Huang Hanliang, Zhang Zichao, Lin Feng. The Application status of transmission and distribution composite poles and towers of China [J]. Fiber Reinforced Plastics/Composites, 2014(3): 66-70.

[5] Xiong Ganhui, Liu Jiangfan,Lin Feng,et al. Development Status of Power Transmission Composite Tower [J]. Insulating Materials, 2013, 64(4): 82-85.

[6] Jiang Shengying, Liang Hao. Analysis and Suggestions on Application of Composite Material in Transmission Line Project [J]. Power \& Energy, 2012, 33(4): 371-374.

[7] Tang Jun. Lightning trip-out of probability analysis for $35 \mathrm{kV}$ transmission line [D]. Guangzhou: South China University of Technology, 2012.

[8] Wang Jianfeng. Research on lightning trip-out rate of $35 \mathrm{kV}$ distribution line [J]. Electric Engineering, 2008, 1(6): 11-26.

[9] Lu Enze, Xu Yuangen. Discussion on Lightning Protection Design for 110kV composite Tower [J]. High Voltage Apparatus, 2013,49(10): 32-36.

[10] LI Zhijun, Chen Weijiang, Jiang Wendong, et al. Research on Lightning Protection of Lattice Composite Material Tower of 110kV Double Circuit Line [J]. High Voltage Engineering, 2015, 41(1):76-83. 